\title{
R\&D Collaboration by SMEs in ICT industries: opportunities and limitations
}

\author{
Rajneesh Narula \\ Professorial Fellow \\ University of Oslo and MERIT
}

FIRST DRAFT (21/10/2000)

paper presented at the International Workshop on

"The New Euro-Asia Pacific Partnership and the Role of SMEs", Singapore on November 14-15, 2000.

\begin{abstract}
Globalisation has systemically affected the way firms undertake innovation. First, there has been a growing use of non-internal technology development, both by outsourcing and strategic alliances. Second, there has been a increasing of cross-fertilization of technologies, such that products are increasingly multi-technology. This is particularly so in the ICT sector. These developments have created both opportunities and threats for the SME. On the one hand, there has been a proliferation in the number and types of SMEs, and enhanced their ability to compete more successfully with their larger counterparts. On the other hand, some of the benefits of globalisation have accrued equally to both groups of firms. This is particularly so for the 'traditional SME' and is associated with the increasingly paradigmatic and maturing nature of the ICT sector. Although SMEs have the advantages of being flexibility and rapid response to change, there are also disadvantages due to their absolute size limitations which may have been enhanced due to increased cross-border competition.
\end{abstract}

Corresponding address:

Professor R. Narula

Centre for Technology, Innovation and Culture (TIK Centre)

University of Oslo

PO Box 1108 Blindern

N-0317 Oslo, Norway

Phone: +4722840600

Fax: +4722840601

e-mail: rajneesh.narula@tik.uio.no 


\title{
R\&D Collaboration by SMEs in ICT industries: opportunities and limitations
}

\author{
Rajneesh Narula \\ University of Oslo
}

\section{$\underline{\text { Introduction }}$}

Information and communications technologies (ICTs) can be regarded from two perspectives. First, they have played a facilitating role in the process of economic globalisation, which I take to mean a process whereby economic entities (both firms and countries) are becoming increasingly interdependent on each other, both across geographic locations and across industries. But its importance should not be exaggerated. On the one hand, it has acted as an 'distance-reducing agent' reducing transaction and communications costs and increasing the efficiency of such transactions. On the other hand, its role is only as significant in globalisation (and perhaps less so) than other globalisation determinants which include transportation technologies and the reduction in trade and investment barriers. Inter alia, the increasing enforceability of cross-border agreements the convergence in technological trajectories across countries, and increased cross-border competition have fundamentally affected the way in which firms are organised, and in the context of this paper, have changed the way (spatially and organisationally) firms organise their innovative activity. There is an increasing international aspect of $R \& D$ activity, and a growth in the use of collaborative $R \& D$ between firms, both within and across borders.

Second, and perhaps more importantly, they have economic significance as a technology per se. By this I refer to ICTs both as products in their own right, and their role as a part of other products and processes. I shall focus my attention henceforth (but not exclusively) on the latter definition. The pervasive role on sectors other than ICT products is associated with what has been called a cross-fertilisation of technologies, whereby multiple technological competences are the norm in what have hitherto been mono-technology products. Cars nowadays have more computing power than the most desktop computers. Fridges, for some strange reason, are now being offered internet- enabled. And so on. However, in such products, ICTs play a peripheral, or even marginal role. in this paper I shall focus on firms for whom ICTs are a central, core technology.

The need for multiple technological competences has increased the knowledge content of products in general, and is partly responsible for the need for higher R\&D resources. One response to the growing breadth of knowledge requirements, has been to utilise non-internal 
means to undertake innovation, and by this I refer specifically to the use of strategic alliances and outsourcing. The facilitating role of globalisation to which I alluded earlier has facilitated firms' use of external resources belonging to non-affiliated firms to reduce, inter alia, innovation time spans, costs and risks, and acquire greater flexibility in their operations. At the same time, however, they have also led to an increased level of inter-firm and cross-border competition, and led to new risks and threats for the technology intensive firm.

This sounds like a paradox. On the one hand, firms seek to specialise in niches, on the other, they need to span several competences, and to be able to be generalists.

This state of affairs has provided a new (or at least reinforced the old) raison d'etre of the SME. Some have argued that new opportunities for collaborative activity allow SMEs to compete more effectively with larger firms. These developments have created both opportunities and threats for the SME. On the one hand, there has been a proliferation in the number and types of SMEs, and enhanced their ability to compete more successfully with their larger counterparts In this paper I will argue that inasmuch as the improvements in communication, and the ease of enforceability of contracts has helped the SME, it has provided at least as much benefit to the large firm too. Nowhere is this more obvious than in collaborative activity with regards innovation. This is particularly so for the 'traditional SME' and is associated with the increasingly paradigmatic and maturing nature of the ICT sector. Although SMEs have the advantages of being flexibility and rapid response to change, there are also disadvantages due to their absolute size limitations which may have been enhanced due to increased cross-border competition. Although my attention will primarily be directed to the collaborative innovative activity of the SME, it should be noted that they cannot be examined in isolation from the large firm. The interdependence of large firms and small firms during the evolution of new technologies and industries is best described as 'dynamic complementarities' (Rothwell and Dodgson 1994). My analysis here is based on in-depth interviews and questionnaire surveys of almost a 100 European technology firms, of which 25 are in the ICT sector. I will use a combination of anecdotal evidence and survey results to illustrate my arguments.

In the next section I will present a taxonomy of types of SMEs, and explain how different types of SMEs tend to be predominate the population of SMEs at a given stage of the evolution of a given industry. In the third section, I will focus on the 'traditional SME' in the ICT sector, and discuss the how these firms utilise R\&D collaboration relative to large firms. I shall attempt to discuss the reasons for the preference of one type of collaboration over 
another, and the limitations of collaboration as an alternative to in-house $R \& D$. The last section presents some conclusions.

Industry evolution and the different types of SMEs

The literature on SMEs indicates that there are a variety of different types of SMEs. I intend to argue here that the prevalence of different kinds of SMEs is associated with the evolution of the dominant technological paradigm. I will make a distinction between three types of SMEs, paying particular attention to the ICT sector.

\section{Types of SMEs}

Keiretsu SME (KeSME) Vertical integration placed SMEs at a distinct disadvantage, in that their existence was simply as a suppliers to the larger, vertically integrated firm, as a intermediate goods producer. They were in the role of specialised supplier, a situation best typified by the just-in-time supplier of the keiretsu. An existence based on the good graces of the large firm, who 'cut the fat' by squeezing on the supplier SME. The SME was only 'in the family' as long as it accepted the edicts vis-à-vis cost, quantity and efficiency of the 'big brother'. I will designate this type of SME as the 'keiretsu SME'.

Traditional SME (TrSME) The 'stand-alone SME', which exists as a 'mini' large firm, acting as a final goods producer is what is often regarded by politicians as the stereotypical, traditional SME. Often in competition with the large integrated firm, but with reduced operations, either in terms of vertical integration, or in terms of horizontal integration. Its existence is predicated on the presence of an efficiency (often technological) not available to the larger firm, or the presence of some other niche advantage (including exclusive access to markets). Vertical integration, and the cost savings there from provided larger, vertically integrated firms with an advantage over SMEs, who must rely on their greater flexibility to compete effectively against the larger firms.

Knowledge SME (KnSME) The third group in my categorisation is the 'knowledge SME'. The knowledge-based firm also acts as a supplier to larger firms, but - as opposed to keiretsu SMEs, is not irrevocably linked to a single network. It bases its existence on supplying specialised knowledge-based assets for sale to small and large firms alike. It typically does not engage in production, and its activities primarily consist of what are best described as R\&D. This group is not new, but its use has now proliferated as a result of the number of radically new technologies which have as-yet undefined dominant technological paradigms, 
and because larger firms cannot afford to undertake in-house developments of all possible technologies and possible technological trajectories.

My argument thus far has illustrated that the three type of SMEs have drastically different objectives, and are suited to particular - and quite different -tasks. However, I will now propose an explanation for the changes in significance of different types of SMEs, and their tendency of particular types of SMEs to be predominant in particular stages of technological evolution in a given industry, again focusing on the ICT sector.

\section{***FIGURE 1 ABOUT HERE***}

Figure 1 gives a stylised presentation of the technological evolution of sectors, utilising two basic measures, technological uncertainty and speed of technological change (Narula 2001). Technological paradigms evolve over time from nascent, pre-paradigmatic and highly uncertain to mature, certain and slow-evolving. Note that because most products and processes are multi-technology based, we refer here to individual technologies. It should further be noted that, despite the multi-technology nature of products and processes, certain technologies are more central or 'core', while others are more marginal (Granstand et al 1997). It is possible, therefore, to argue that industries demonstrate a similar evolution. It is self evident that the framework in figure 1 is a stylised one, and that sectoral evolution is a continuous rather than discrete process. I will now discuss how the structure of industry - in terms of size of firms, and in particular, predominant type of SME - varies with the evolution in the technological characteristics of the ICT sector. Figure 2 illustrates - in the same context as figure 1 - the types of SMEs that tend to predominate during each stage of industry evolution.

\section{***FIGURE 2 ABOUT HERE***}

\section{Quadrant A}

New technologies begin from a basic idea, often, a fundamental invention or technological breakthrough based on a idea which may have hitherto been a scientific theory. However, at an early stage, the technology is impractical. Its potential use is not obvious, it is not close enough to being commercial, and/or may still remain at an early stage of development. Current research interests in superconductors illustrates this well. Only the largest firms with 
large resources invested in basic research (such as Bell Labs, or IBM) are likely to be willing to invest in a project such as this, given that neither the time-horizon is practical, nor what variation in the technology is likely to win. There exist so many research trajectories and combinations of materials, from ceramics to semiconductors, that it does not serve most firms to invest in such research. Apart from large MNEs, university departments and publicly funded facilities are likely to engage in such long-term investment.

As the rate of technological innovations and breakthroughs become more rapid, and a commercially viable product becomes closer to reality, large firms and universities may create (or may have to create) KnSMEs as spin-offs, as important scientists involved seek more control of their inventions and the possible returns. Scientific personnel at the cutting edge of new technologies are rare, and this may be the only way to keep them. In addition, large laboratories and firms do not act as the best incubators for new, nascent technologies, which need more flexibility and a more organic organisation, a primary advantage of an SME. Besides, by doing so, it insulates the large firm from taking additional risk and minimising investment, by allowing external agencies in sharing the costs. The SME can seek additional resources from venture capitalists and public funds, which might not otherwise be available. At the same time, the large firm often have an option to acquire the discoveries of the KnSME if it makes a move towards more commercialisable technologies. Nonetheless, the basic nature of the research means that few such KnSMEs will exist, outside dedicated universitybased research centres.

\section{Quadrant B}

Eventually, however, as innovation move towards the point of resulting in patents which may be commercially exploited, an increase in such KnSMEs may be expected. Prototypes of products now exist, and the SME needs not only technological resources, but also manufacturing and managerial personnel and expertise. Increased financial flows from both large firms and venture capitalists will fuel the movement of the best scientists, as there is a race to establish a dominant technology, and thus to define the paradigm. This is the situation that the biotechnology industry finds itself today, and robotics. The software industry was also at this stage in the late 1970s and early 1980s. Eventually, as the KnSMEs begin to grow, spin-offs will begin from these companies, created additional KnSMEs. Large firms will begin to acquire the more successful companies in these sectors, attempting to internalise and apply these new technologies to their existing products and processes. Acquiring these KnSMEs allows the larger firm to integrate the new technology to their 
existing $R \& D$ activities, and, it is hoped the large resources available to the big company will help to reduce the 'distance to market'.

Toward the end of quadrant B, products based on the new technologies begin to enter the market, although they will tend to be of a specialised nature, due to their high cost of production. There is a high concentration, as only a few firms will have the technological competences necessary. Technological change remains rapid, and leadership moves from one company to another, with no clear dominant player. Production is predominantly undertaken by SMEs (TrSMEs), which operate on a small scale, since competitive advantage is based on technological assets, rather than price.

\section{Quadrant C}

By quadrant $\mathrm{C}$, the technology will have been diffused, and the technological difficulties of large scale production will have been overcome. Production in small batches will gradually be replaced by large-scale production. These are either TrSMEs which have rapidly expanded their operations, or by large firms that have acquired the technology through M\&A of SMEs. Where the technology in question is not central (but more marginal) to the industry of the large firms, they may prefer to use quasi-external means, both for production and technology development. This is why there is a growth of Keiretsu-type SMEs (KeSMEs), which act as suppliers to the large firms. This type of SME becomes increasingly important as the technology becomes codifiable and increasingly mature, such that large firms seek to use outsourcing. The dominance of KnSMEs in technological change declines, except perhaps in niche sectors. Much of innovation moves towards development-type work, and incremental improvements of increasingly mature products.

\section{Quadrant D}

By quadrant $\mathrm{D}$, the technology is mature. Technical change is now slow, with minor but consistent innovations over time, and can be regarded as post-paradigmatic. The technology is to a great extent codifiable, widely disseminated, and the property rights are well-defined. Innovation is rarely patentable in these technologies, where applications development account for most innovatory activity. Competition shifts towards price, economies of scale, and downstream activities in order to add value, as the original product is priced as a commodity. SMEs simply do not have the size advantages to engage in production (except perhaps in specialised niches), and TrSMEs are the exception rather than the rule. The main opportunities for SMEs are as keiretsu-type MNEs, acting as specialised suppliers to large firms. 


\section{$\underline{\text { Traditional SMEs in the ICT sector }}$}

In this section we will address the question of $R \& D$ collaboration by ICTs firms, illustrating the differences between SMEs and larger firms. We focus on what we have earlier described as 'traditional SMEs'. My discussion is based on data that derives from a larger ongoing survey being conducted on the internationalisation of R\&D by European based MNEs. Currently, over 100 firms have been surveyed, through mailed questionnaire surveys and 32 firm interviews. The criteria for selection of these firms has been a) That they were majorityEuropean owned as of 1998, b) engaged in manufacturing, c) have annual R\&D expenditures greater than (approximately) US\$1 million and/or 10 full-time R\&D employees. Approximately $25 \%$ of our survey involved ICT firms, about half of which are SMEs.

The firms in my sample, like most ICT firms, can be classified in quadrant C, although certain industries have progressed towards quadrant $\mathrm{D}$ (PC manufacturers, hard disk technologies), where products are mature and compete mainly on price, having taken on a commodity-type nature. It is true that while new technologies do exist that are still preparadigmatic (nano-electronics, artificial intelligence, neural networks), but broadly speaking they are predominantly paradigmatic. Clear dominant technologies have presented themselves, and de facto standards established. Unambiguous technological trajectories exist, and most innovatory activity is focused around the dominant paradigms. Technological change remains rapid, but mainly through incremental, rather than radical innovation. Innovation also tends, for the most part, to be undertaken either in applied research, or in development, and rather rarely in basic research. Since innovation is built around clear trajectories, the nature of the incremental innovation is known, what is unclear who will be first to the market. Although property rights are clearly defined in quadrant $\mathrm{C}$, the rapidity of change means that firms maintain their competitive advantage by being first to innovate and exploiting the lead time of being 'first'. In our sample, the life cycle of products averaged around 12-18 months, a pace usually dictated by 'major players' (i.e. large firms).

\section{***FIGURE 3 ABOUT HERE***}

Thus far, these tendencies apply universally to all firms in quadrant C. However, R\&D in quadrant C (and in ICTs in particular) is resource intensive, both in terms of capital and knowledge. Most products are multi-technology in nature, and multiple competences are 
needed. Figure 3 illustrates the kinds of technologies that a typical ICT firm may require. Few firms, regardless of size, can afford to maintain R\&D facilities with world-class competences in so many different sectors. This is particularly so in the case of SMEs, which by definition have limited resources. Even if SMEs maintain twice the level of R\&D intensity as a large firm in the same industry (which typically might be 5\%), a company of 500 employees might maintain an R\&D department of about 50 people, while a large firm with 5000 employees have an R\&D facility of 250 people.

\section{***TABLE 1 ABOUT HERE***}

Table 1 gives a rough idea of the differences in size between the large firms and the SMEs. Large firms in our sample spent 5 times more on R\&D than the SMEs. However, in terms of R\&D employees, large firms were on average only three times larger. Nonetheless, the average size in terms of R\&D employees of SMEs in my sample was 42 . There are only so many specialisations that an SME can maintain with such a small absolute R\&D headcount. There is a certain minimum threshold size of a research group within any area, and this represents a real constraint to SMEs. In addition - and this is true for firms of all sizes there is no guarantee that the research group in any given facility will in fact consistently innovate at the technological frontier, and within the dominant paradigm, even if world class researchers are present. In other words, there are cognitive limits on what firms can and cannot do (Pavitt 1998). Firms therefore are dependent on the last-best (i.e., state-of-the-art) innovation. If a firm is engaged in developing an innovation in a given technological paradigm, it must strive to improve (or at least take into account) not its own last-best innovation, but the last-best innovation that has been patented, or that is the dominant design on the market ${ }^{1}$, even if this was created by another firm. Thus its path-dependency is always tempered by the state-of-the-art, and this means that roughly speaking technological trajectories of different firms within any given technological paradigm are similar.

There are therefore two pressures on ICT firms - firms are forced to maintain an equivalent breadth of $R \& D$ competences as other firms in the same industry, and at the same time maintain their innovative activities at the industry rate of evolution. The benefits of smallness - which are variously associated with greater flexibility and rapid response compensate for some of the disadvantages of size, and may allow SMEs to maintain the rate

\footnotetext{
${ }^{1}$ Numerous examples of technically sub-optimal innovations defining the technological trajectory exist (e.g., Betamax vs. VHS, Macintosh vs. PC). Perhaps the best documented example is of the QWERTY keyboard (David 1985)
} 
of technological change. But they do not necessarily help SMEs when it comes to the absolute limit on its resources.

Keep in mind too, that SMEs have also to devote resources to other aspects of the value chain. They must seek to achieve economies of scale in production, and also to effectively market their products, and provide support services. In quadrant $\mathrm{C}$, market share considerations are at least as important as technological assets - it is insufficient simply to have the best product, if no one will buy it. More importantly, if a competitors technology is accepted as the industry standard, it can threaten the existence of the firm.

It is impressive, nonetheless, that the SMEs in our sample employ more people relative to their R\&D expenditures than large firms, and the answer lies to some extent in their greater use of non-internal R\&D sources. Larger firms tend to use a smaller percentage of their R\&D budgets (on average 12.4\%) to outsource and engage in strategic alliances than SMEs which utilise on average $21.9 \%$ of their R\&D budget (Table 1). The limitation in resources, and the need to maintain the firm's position on the technological frontier of the various technological areas that it requires is mainly responsible for the growth in the use of non-internal R\&D activities in both large and small firms. Our use of the term 'non-internal' is a deliberate one, and is intended to include both external activities (arms-length relationships such as licensing, R\&D contracts, outsourcing - and other customer-supplier relationships) and quasi-external activity (such as strategic alliances, which is taken to include a myriad of organisational modes [Narula and Hagedoorn 1999]). Non-internal activities, apart from the obvious benefits of exploring new areas and instigating radical change, have the advantage of being a 'reversible' form of investment (Gambardella and Torrisi 1998). The capital needed is smaller, and the risks are substantially reduced, and in case of failure or organisational crisis, limited damage is inflicted on the primary operations of the firm. Nonetheless, the tacit nature of innovation, and the risks associated with loss of technological competitiveness, encourage a high level of in-house R\&D activity.

External acquisition of technology is most easily done when the technology behind the product is codifiable and standardised and for which multiple non-distinguishable sources of these inputs are available (Narula 2001). The same argument holds true for R\&D activity, since $R \& D$ output is partly tacit, externalisation of $R \& D$ means that the firm only gets the codified results, not the accumulated person-embodied skills. As has been noted elsewhere, even where firms outsource, they maintain a minimum level of in-house capacity in those technologies in order to decipher and utilise them (Veugelers 1997). In other words, R\&D outsourcing is only undertaken where doing so is cost-effective AND does not threaten the 
competitive advantages of the company. Having a single source or single buyer may prove to be most cost-effective, but it is generally accepted that low costs do not always translate to the best technology.

The manner in which firms select external vs. internal R\&D acquisitions is associated with the centrality of the technological competence to the firms activities (Narula 2001). Firms will, ceteris paribus, prefer to undertake innovative activities in their distinctive competences through in-house R\&D. Although there is considerable overlap (figure 3), broadly speaking niche and marginal competences are strategically less significant, and can be undertaken through alliances. However, the strategic importance of these technologies determines to what extent their development can be externalised. This, in turn, is determined by the extent to which the technology is tacit, the extent to which collaboration is required to utilise it, and to what extent the partners activities need to be monitored.

Background competences are, by and large, the area where outsourcing is primarily used. In general, it would seem firms prefer to undertake research in their distinctive competencies in-house as much as possible. There is, however, considerable overlap in the use of in-house $R \& D$ and alliances for niche competences, and between outsourcing and alliances in marginal/peripheral competencies. SMEs tend to be more concerned about their loss of technological assets than large firms. SMEs tend to use non-internal means with a great deal of care, bordering, in some cases, on paranoia. One firm said,

'Because we do not have the resources [ourselves, and have to outsource], we make sure none of our partners has enough of our technology to become a competitor. We provide the macro-specifications to one partner, which does the design. But we have a different company to do the manufacturing of the relevant sub-assembly. We make sure that no company is responsible for more than one sub-assembly, and always pick companies smaller than us.'

Another manager agreed;

"we use more than one supplier, our products are based on several boards. Each supplier produces only one board, because we don't want any supplier to have access to our complete product. We might be able to get a lower price, but we don't want to be in a position that the supplier is able to become a competitor. Nondisclosure agreements aren't enough."

In general, the vulnerability due to smaller size means that SMEs have to be more wary of alliances. One of the SMEs in our sample considered alliances unacceptably risky:

"These competencies are too important to us....we have spent many years building our strength in these sectors...frankly we have world class 
competences......I am loathe to consider letting anyone near our technology. We only use alliances [in these areas] if we have to."

In general, however, SMEs use non-internal means to a larger extent than large firms, because they can maintain sufficiently high level of in-house competence in only a few (or even a single) technological area. This represented an advantage of the SME, according to one manager who argued,

'we are not married to a given technology, and that is precisely why we are successful. If we did our own research, we would have a vested interest in a particular technology, even if it is not the best, and this would eventually become a problem.'

Thus, there are many more technologies which they have to acquire externally. The use of alliances in connection with niche sectors was, in general, associated with firms that had limited R\&D facilities and/or considered that there was a large technological gap between their technological competencies and the market leaders. SMEs considered alliances as a way of extending their technological competences more than large firms, but only when they were unable to do so through outsourcing. For instance, one medical equipment manufacturer did not have the resources to invest in the next generation of displays. Although LCD technology has become more mature over the last 5 years, it remains capital-intensive, and proprietary technology rests with a handful of companies. It therefore sought an alliance with a US company which is a market leader in medical equipment, many times their size. The US firm did not currently compete with them in their particular product segment, and agreed to share the technology and to distribute their products in the US. As a manager pointed out,

"It's a risk [to ally with such a large player], but the cost of developing our own display systems would use up almost our entire R\&D budget for a couple of years... and our old product range was [beginning to look] old...[They]...have the technology lying around, because they have more people in their R\&D facilities than we have in our entire company... [if they wanted to] they could buy us out, whether we had a partnership with them or not [so it doesn't matter whether or not we partner with them]."

The point I want to make here is that first, there is a limit to how much of a firm's R\&D activities can be externally acquired particularly due to technological and strategic considerations. Second, even if costs are reduced through the use of non-internal means, they remain non-trivial, and the constraints of absolute limits of resources remains. 
Both large and small firms have similar motives to undertake inter-firm $R \& D$ collaboration (Table 2). The primary motivation for both groups of firms was not considered to be the reduction of risks or costs, but the reduction of innovation time span, and the access to complementary technologies. However, larger firms are in a better position to establish partnerships, because they have more to offer. SMEs have fewer technological assets with which to barter, while the technological portfolio of large firms is larger, and besides they can offer cooperative agreements at other levels too, from either production or their marketing and sales operations. This is apparent from Table 3.

\section{***TABLE 3 ABOUT HERE***}

Where SMEs concentrate their activities in-house, they are still forced to consider alliances with larger firms, simply as a means of getting access to marketing and sales channels. A telecommunications equipment company explained,

'Although we do not need anyone for technology, we are not able to offer a 'suite' [an integrated package of products]. The way of the future is systems integration, and it is the key. Customers want our equipment to work in tandem [with products of other manufacturers]. Our competitors are all large and can offer an integrated package, we can't. So we are looking for a partner who will sell our product, but we are faced with a dilemma, because the only companies who make [the other parts of the suite] are our competitors .,2

In general, both large and small firms show a preference to outsource applied research and product development to public research institutes and universities, because of the fear of giving away their technology to a competitor, or potential competitor. Although our data is by no means conclusive, anecdotal evidence suggests that SMEs tend to engage in fewer strategic alliances with other firms, preferring to outsource wherever possible. It should be noted that there is a lower limit to the extent to which any firm (but particularly SMEs) can use non-internal sources as a substitute for internal R\&D. Both alliances and outsourcing require complementary resources. Some level of in-house capacity is essential to absorb the externally acquired information. Furthermore, alliances in particular (compared to outsourcing) require considerable managerial resources, not just because of the collaborative aspect, but also because alliances tend to be used where technology is tacit. Again, limited human resources means there is a limit to what percentage of a smaller absolute size of personnel can be devoted to managing alliances. 


\section{The need for international sources of technology}

However, the globalisation of markets and the growth of cross-border competition places SMEs at another disadvantage vis-à-vis large firms in another way. As economies have become interdependent, firms (of all sizes) need access to the innovation systems in other locations. Firms need to supplement their ownership advantages by seeking location-specific assets in other countries than their own. That is, they may seek to augment their home-based assets through locating some extent of their innovatory activities where there is a high level of agglomeration of innovation in their industry. In addition, product adaptation and development is most effectively undertaken closer to the market. Establishing R\&D facilities - even of a 'listening post' variety - provides a potentially valuable opportunity to internalise spillovers from the research facilities of other players in the ICT sector in that location, both public and private.

However, in general, SMEs tend to concentrate their production and sales in their home country, much more so than large firms, and do not have the resources necessary to engage in home-base augmenting activity. Although some of the SMEs in our company have established $R \& D$ facilities abroad (Table 1) in response to increasing need to monitor the activities of competitors, and to be responsive to particular market conditions, a dispersion of R\&D activities across the globe also requires extensive coordination between them - and particularly with headquarters- if they are to function in an efficient manner with regards to the collection and dissemination of information. This acts as a centripetal force on R\&D, and accounts for a tendency of firms to locate $R \& D$ (or at least the most strategically significant elements) closer to headquarters. As table 1 shows, even though almost a third of the SMEs have overseas R\&D, these are on average very small indeed. Even in the US, which has the largest concentration of ICT firms, and which is the largest market, SMEs had less than 10 $\mathrm{R} \& \mathrm{D}$ employees on average compared with almost a 100 employees on average for larger firms.

Strategic alliances do provide a possible alternative to undertake such activities. Previous research has shown that firms do in fact use strategic technology alliances as a means to tap into other locations' innovation systems. Firms tend to select partners who provide the best opportunities for learning, regardless of their location (Narula and Hagedoorn 1999). However, such growing complex linkages, both of networks internal to the firm, and those

\footnotetext{
${ }^{2}$ Two months after the interview, this SME was acquired by a large competitor.
} 
between external networks and internal networks, require complex coordination if they are to provide optimal benefits (see Zanfei 2000 for a discussion). Such networks are not only difficult to manage, but also require considerable resources (both managerial and financial). It is no surprise, therefore, that external technology development is primarily the domain of larger firms with greater resources, and more experience in trans-national activity (Hagedoorn and Schakenraad 1994, Castellani and Zanfei 1998). SMEs are generally not in a position to undertake such activity. While it is true that ICTs have improved coordination, the importance of 'being there' and having direct contact remains especially important in $R \& D$, where much of the knowledge is not only tacit and largely uncodifiable, but embodied in people.

Thus it seems reasonable to expect that large firms to undertake a higher level of R\&D overseas, although in proportion this may be the same as smaller firms. Indeed, this is the conclusion made by Patel and Vega (1999), among others. Small firms are constrained by their limited resources - the expansion of R\&D activities- both at home and in overseas locations requires considerable resources both in terms of capital investment, and managerial resources which these firms simply do not have. Ceteris paribus, large firms have more money and resources to use on overseas activity. Large firms are also more likely to have more linkages with the domestic science base, and tend to have a well developed network of supplier firms at home. But as I have highlighted earlier, SMEs are not always in a position to partner with large firms, since they have relatively little to offer in exchange, and face a strategic threat even if they were to do so. SMEs need to be able to scan overseas locations and learn from their competitors and markets no matter where they are. This is particularly important in industries where technological change is rapid.

\section{Concluding remarks}

This paper has highlighted the increasing imperative of ICT firms to expand their portfolio of technological competences, and that this applies to SMEs as much as it does to large firms. Fortunately, reduced costs of enforcing agreements, the decline in barriers to trade and investment and the improvements in communications have improved the efficacy of cooperative ventures, especially for R\&D.

I have focused on 'Traditional SMEs' in the ICT sector, which are engaged in direct competition with larger firms, and broadly speaking are 'mini-large firms'. Both groups of firms need roughly the same breadth of technological competences, as multi-technology products are the norm in the ICT sector. For both groups of firms, maintaining such a large 
portfolio of technological competences is difficult, but more so for the SME. The use of noninternal technology development through outsourcing and alliances has provided benefits for both types of firms, but particularly so for the SME.

SMEs tend to maintain a smaller group of in-house technological competences, and are generally able to leverage their limited $R \& D$ resources more efficiently. They tend to use almost twice as much of their $R \& D$ expenditures towards $R \& D$ collaboration than large firms. However, there are cognitive limits to what SMEs can do, and how much they can use noninternal $\mathrm{R} \& \mathrm{D}$, due to their limited resources due to the absolute size limitations. Nonetheless, the more successful SMEs have been able to maintain their competitive position through a more astute use of non-internal $R \& D$, with less in-house $R \& D$ than larger firms.

However, collaboration has its price. First, because even where non-internal means are used, some level of in-house competence must be maintained in order to understand and integrate the various technologies together. Second, most R\&D alliances have a very low success rate. A failure rate of $50 \%$ was judged by firms in my sample to be very good indeed'. For a large firm, these losses are easier to accept, who often have multiple, redundant, backup agreements with several firms. In addition, large firms have more to offer in a partnership, and can easily find alternative sources, compared with SMEs.

SMEs are more careful about picking partners, because they have limited opportunities to fail. There are also strategic reasons to be careful: partnering with a larger firm can lead to a loss of technological competence.

It seems that there is a limit to how much of a firm's R\&D activities can be externally acquired particularly due to technological and strategic considerations. In addition, even if costs are reduced through the use of non-internal means, they remain non-trivial, and the constraints of absolute limits of resources remains.

Firms in the ICT sector all have a growing need to monitor the innovation systems of other countries than their own, and to be located close to both their markets, and their competitors to maintain their competitiveness. They need to do so both through $\mathrm{R} \& \mathrm{D}$ facilities abroad, and through alliances. However, SMEs are again constrained by their resources. Even alliances require some level of physical presence, and the threshold level to establish such facilities is often prohibitively high for SMEs.

Traditional SMEs in the ICT sector are an endangered species. In the long run, these firms are faced with 3 options: expand, be acquired, or specialise. This is in fact what might be predicted from my discussion of industry evolution. As technologies become more mature and diffused, competition shifts away from technological excellence per se, and towards price. 
Size and costs become more critical. As such, if SMEs specialise, they can maintain their position on a technological basis where small size and flexibility allow SMEs to be at least as innovative as large firms, if not more. 


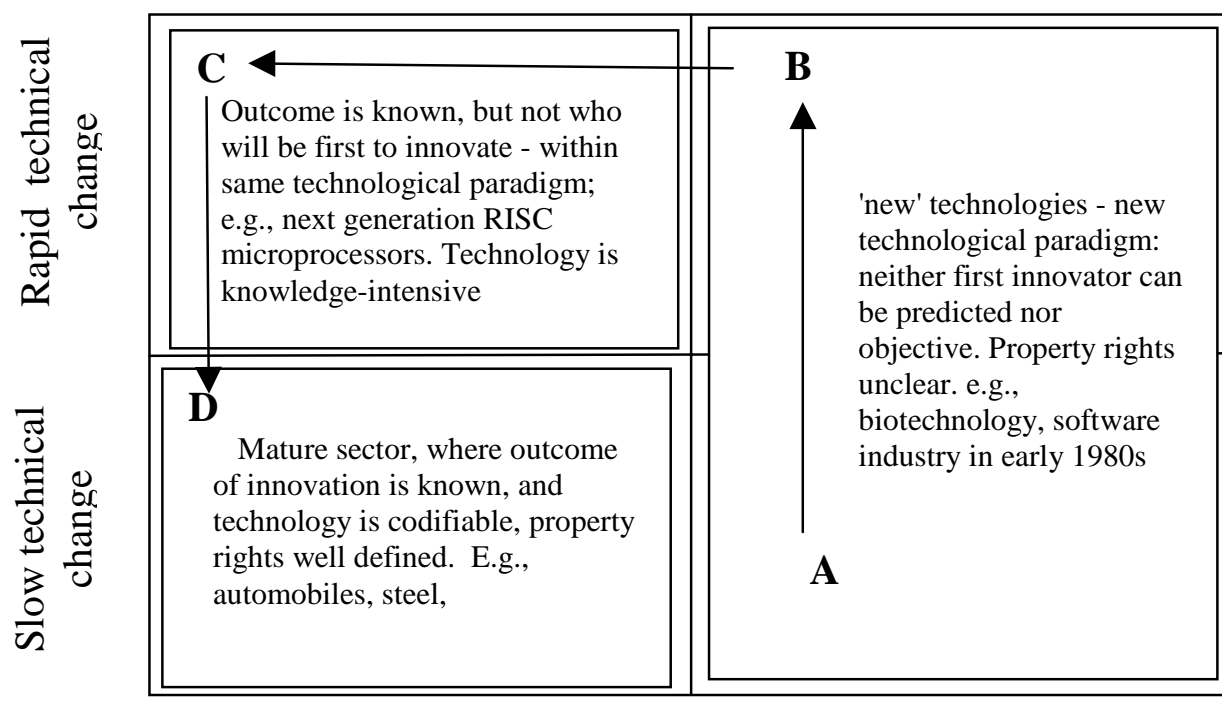

Low uncertaintv High uncertaintv

Figure 1: Technological evolution with a given paradigm

\begin{tabular}{|l||l|}
\hline Quadrant C & Quadrant B \\
KnSME & KnSME \\
TrSME & TrSME \\
KeSME & Quadrant A \\
\hline Quadrant D & KnSME \\
KeSME & \\
\hline
\end{tabular}

Figure 2: Types of SMEs at different stages of an industry's evolution 


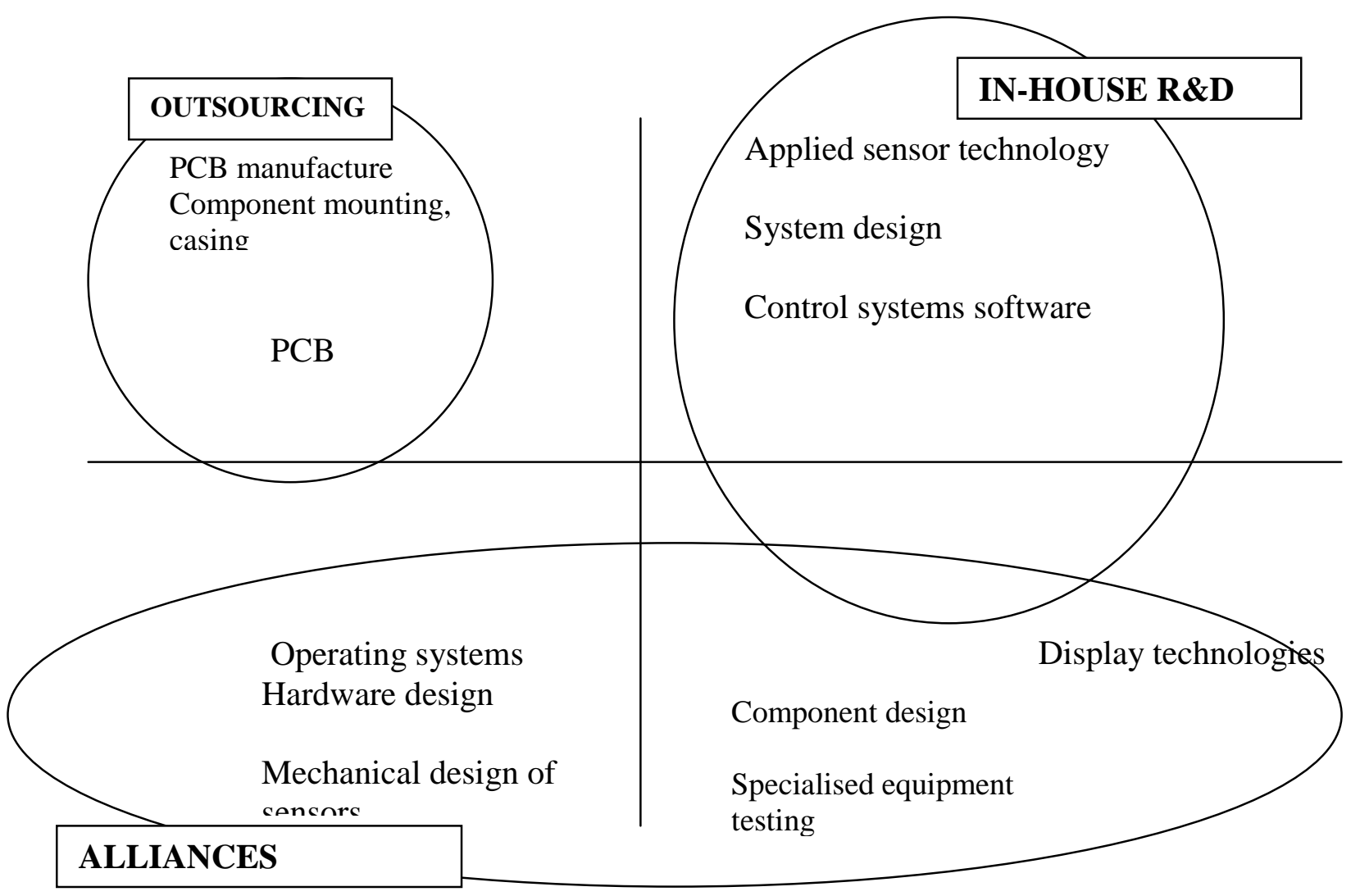

Note: No attempt has been made to locate technologies on a relative basis within any given quadrant.

Figure 3 Distribution of competences of an ICT firm, based on managers' perceptions 


\begin{tabular}{|c|c|c|}
\hline & SMEs & $\begin{array}{l}\text { Large } \\
\text { irms }\end{array}$ \\
\hline Mean R\&D expenditure & 4.15 & 21.54 \\
\hline Mean R\&D employment & 42 & 129 \\
\hline$\%$ of R\&D in home location & 90.7 & 57 \\
\hline$\%$ of firms with overseas R\&D labs & 36.4 & 77.8 \\
\hline $\begin{array}{l}\text { Percentage of firms with R\&D facilities in the US } \\
\text { average size of R\&D facilities in the US (employees) }\end{array}$ & $\begin{array}{r}27.3 \\
8.2\end{array}$ & $\begin{array}{l}66.7 \\
96.5\end{array}$ \\
\hline$\%$ of R\&D acquired externally & 21.9 & 12.4 \\
\hline $\begin{array}{l}\% \text { of firms with }<20 \% \\
\text { external acquisition } \\
\text { Table } 1 \text { Some basic indicators }\end{array}$ & 28.6 & 100 \\
\hline
\end{tabular}

\begin{tabular}{|c|c|c|c|c|}
\hline & mean & $\begin{array}{l}\text { SME } \\
\% \text { major or } \\
\text { crucial importance }\end{array}$ & mean & $\begin{array}{l}\text { rge firms } \\
\% \text { major or } \\
\text { crucial importance }\end{array}$ \\
\hline reduction of costs & 2.4 & 40 & 3.0 & 28.6 \\
\hline reduction of risks & 2.5 & 30 & 2.9 & 14.3 \\
\hline reduction of innovation time & 3.4 & 70 & 3.3 & 42.9 \\
\hline access to markets & 2.4 & 30 & 2.2 & 33.3 \\
\hline access to complementary technology & 3.6 & 60 & 4.6 & 100 \\
\hline setting standards & 2.7 & 30 & 2.7 & 42.9 \\
\hline
\end{tabular}

Table 2 The importance of different R\&D motivations for ICT firms

What kind of research do you undertake with your partners?

\begin{tabular}{|c|c|c|}
\hline & $\begin{array}{l}\text { SMEs } \\
\% \text { of firms th } \\
\text { often' or 'mo }\end{array}$ & $\begin{array}{l}\text { Large } \\
\text { Firms } \\
\text { spondec } \\
\text { the tim }\end{array}$ \\
\hline basic research & 0 & 0 \\
\hline applied research & 50 & 14.3 \\
\hline development & 50 & 71 \\
\hline design & 10 & 43 \\
\hline production and marketing & 20 & 71 \\
\hline
\end{tabular}

Table 3: Kind of R\&D activities that firms prefer to undertake with partners. 


\section{References}

David, P. (1985) 'Clio and the economics of QWERTY' American Economic Review, Vol 75, no 2 , pp 332-7

Dosi, G (1982) 'Technological paradigms and technological trajectories: a suggested interpretation of the determinants and directions of technical change', Research Policy

Gambardella, A. and Torrisi, S. (1998) "Does Technological Convergence imply Convergence in Markets? Evidence from the Electronics Industry", Research Policy,

Granstrand, O., Patel, P. and Pavitt, K. (1997) "Multi-Technology Corporations: Why They Have "Distributed" Rather Than "Distinctive Core" Competencies", California Management Review, Summer 1997, Vol. 39, No. 4: 8-25

Hagedoorn, J. and Schakenraad, J. (1994) the effect of strategic technology alliances on company performance, Strategic Management Journal, vol.15., pp. 291-311.

Kuemmerle, W. (1996) Home Base and Foreign Direct Investment in R\&D, Unpublished PhD dissertation, Boston: HBS

Narula, R. (1999) Explaining Strategic R\&D alliances by European firms, Journal of Common Market Studies, Vol 37, no 4, 711-23

Narula, R. (2001) Choosing between modes of non-internal technological activities by firms: some technological and economic factors, Technology Analysis and Strategic Management, forthcoming

Narula, R. and Hagedoorn, J. (1999) Innovating through strategic alliances: moving towards international partnerships and contractual agreements, Technovation, Vol 19, pp 283294

Patel, P. and Vega, M. (1999) Patterns of internationalisation and corporate technology: location versus home country advantages' Research Policy, Vol 28. pp. 145-155

Pavitt, K. (1998) Technologies, products \& organisation in the innovating firm: What Adam Smith tells us and Joseph Schumpeter doesn't Industrial and Corporate Change, 7:433452

Rothwell, R. and Dodgson, M (1994) Innovation and Size of Firm, in Dodgson, M. (ed) Handbook of industrial innovation

Veugelers, R. (1997) Internal R\&D expenditures and external technology sourcing, Research Policy, Vol 26, pp 303-315

Zanfei, A. (2000) Transnational firms and the changing organisation of innovative activities, Cambridge Journal of Economics, Vol 24, forthcoming 